\title{
Therapeutic potential of flavonoids in spinal cord injury
}

PengZhang ${ }^{1}$, Christian Hölscher ${ }^{2,3}$, Xun Ma ${ }^{1}$

1. Department of Orthopaedics, The Affiliated Shanxi Da Yi hospital of Shanxi Medical University, Taiyuan, Shanxi province, China.

2. Biomedical and life science, Faculty of Health and Medicine, Lancaster University, Lancaster LA1 4YQ, UK.

3. Second hospital, Neurology department, Shanxi Medical University, Taiyuan, Shanxi province, China.

Short title: Flavonoids in spinal cord injury

Corresponding author:

Prof. Xun Ma

Shanxi Da Yi Hospital,

Shanxi Medical University,

99 Long Cheng street,

Taiyuan, Shanxi, 030032 P.R. China

Tel: international +86-351-8379003;

Fax: international +86-351-8379099;

Email:xunmajk@163.com 


\begin{abstract}
Spinal cord injury $(\mathrm{SCl})$ is a catastrophic event that can profoundly affect a patient's life, with far-reaching social and economic effects. A consequential sequence of $\mathrm{SCl}$ is the significant neurological or psychological deficit, which obviously contributes to the overall burden of this condition. To date, there is no effective treatment for $\mathrm{SCl}$. Therefore, developing novel therapeutic strategies for $\mathrm{SCl}$ is highly prioritized. Flavonoids, one of the most numerous and ubiquitous groups of plant metabolites, are the active ingredients of traditional Chinese medicine (TCM) such as Scutellaria baicalensis Georgi (Huang Qin) or Ginkgo biloba(Ying Xin).Accumulated research data show that flavonoids possess a range of key pharmacological properties such as anti-inflammatory, antioxidant, anti-tumor, anti-viral, anti-cardiovascular disease, immunomodulatory, and neuroprotective effects. Based on this, the flavonoids show therapeutic potential for $\mathrm{SCl}$ diseases. In the following article, we will review the pharmacological properties of different types of flavonoids for treatment of spinal cord injury diseases, and potential underlying biochemical mechanisms of action will also be described.
\end{abstract}

Key words: Flavonoids; Spinal cord injury; Pharmacology; Anti-inflammatory; Antioxidants; Anti-apoptosis; Neuroprotection. 


\section{Introduction}

In modern society, the estimated annual global incidence of spinal cord injury (SCl) is approximately 15-40 cases per million and is increasing (Singh et al., 2014; Sekhon and Fehlings, 2001). SCI is a catastrophic event that can profoundly affect a patient's life, with far-reaching social and economic effects(Sekhon and Fehlings, 2001). A consequence of SCl is the significant neurological or psychological deficit, which obviously contributes to the overall burden of this condition (Evaniew et al., 2015). Along with the development of neurobiology, materials science, pharmacology, and other related sciences, great progress has been made in the prevention and treatment of $\mathrm{SCl}$.

Significant progress has been made to relieve the symptoms of $\mathrm{SCl}$ and the suffering of patients, which are achieved by preventing injury progression (Silva et al., 2014; Zhang et al., 2016). At present, in the early phase, the conventional treatment of spinal cord injury in clinic is surgical therapy combined with high doses of methylprednisolone (MP). The surgical procedures are able to decompress the spinal cord and restore the normal anatomy of the spine and stability(Ahuja, Martin, and Fehlings, 2016).Although MP has many advantages such as maintaining the blood-spinal cord barrier, enhancing spinal cord blood flow, and limiting the inflammatory response(Suberviola et al., 2008), potential harms of MP include risks of infections and gastrointestinal bleeding, potentially leading to increased mortality. Therefore, most current guidelines do not recommend routine administration of MP for acute SCI(Hurlbert et al., 2015; Hurlbert, 2014; Walters et al., 2013). Meanwhile, various other novel strategies for SCI repair have emerged and received considerable research attention, including drug therapy such as Gangliosides(Chinnock and Roberts, 2005), Erythropoietin (EPO)(Nekoui et al., 2015), Minocycline(Aras et al., 2015), Vitamin B12(Petchkrua et al., 2003), Tacrolimus(Pan et al., 2013); cell therapy such as transplantation of neural stem cells(Cheng et al., 2016), bone marrow-derived mesenchymal stem cells(Yousefifard et al., 2016), adipose-derived mesenchymal stem cells(Kim et al., 2015), Schwann cells(Oraee-Yazdani et al., 2016), olfactory ensheathing cells(Li et al., 2015); gene modification technique therapy such as nerve growth factor (NGF)(Zhai et al., 2015), neurotrophin-3(Hanna et al., 2016), brain-derived neurotrophic factor (BDNF)(Wang, Liao, and Li, 2010), glial cell line-derived neurotrophic factor (GDNF)(Chou et al., 2014),or ciliary neurotrophic factor(Abbaszadeh et al., 2015).However, it is worth noting that most of the treatments are still at the research stage, and are not ready for use in the clinic. Thus, the treatment of $\mathrm{SCl}$ is currently a significant challenge in the clinic and in research around the world. To date, there is no majorly effective treatment for SCI(Zhao et al., 2011).

As a productive natural resource for drug discovery, Traditional Chinese Medicine (TCM), has many thousands of years of history in clinical applications in China and other Asian countries, plays a role in complementary and alternative medical systems, and has an advantage for treatment of SCl due to a large number of experimental studies(Liu et al., 2015; Boots, Haenen, and Bast, 2008; Manach et al., 2005). Although TCM therapy could not replace surgical procedures, it could be play a supportive role in treating $\mathrm{SCl}$. Scutellaria baicalensis Georgi (Chinese name Huang Qin), Quercetin(Chinese name Hu Pi), Puerarin (Chinese name Ge Gen), Safflower Yellow (Chinese name Hong Hua Huang), -Epigallocatechin gallate (Chinese name $\mathrm{Er}$ Cha Su), Anthocyanins (Chinese name Hua Qing Su), Ginkgo biloba (Chinese name Ying Xin), and 
numerous others. TCM has provided classic herbal medicine for treating spinal cord injury diseases in the clinic for many years. It was found that the main active components are flavonoids by using modern pharmacological discovery. Flavonoids, one of the most numerous and ubiquitous groups of plant metabolites, have anti-inflammatory, antioxidant, neuroprotective physiological activity as demonstrated in experimental studies. In addition, a number of studies have found that flavonoids have therapeutic potential in SCl. However, the molecular mechanisms involved the effects shown by TCM still remain unclear, and it can be challenging to systematically identify them using modern pharmacological and biochemical techniques(Liu et al., 2015).In the following paragraphs, we will review the pharmacological actions of different types of flavonoids for the treatment of spinal cord injury diseases, and some potential underlying biochemical mechanisms of action will also be described.

\section{Pathophysiology of SCI}

Patients with spinal cord injury often experience severe loss of function and a profoundly impaired quality of life. More and more research has focused on elucidating the mechanisms and complex pathophysiologic processes of $\mathrm{SCl}$. Pathophysiological events occurring after $\mathrm{SCl}$ include a primary mechanical injury and a secondary injury.

A primary mechanical injury often results from a mechanical impact to the spine, concomitant with or followed by compression, contusion, stretching or kinking of the spinal cord(Stahel, VanderHeiden, and Finn, 2012).This phase refers to the immediate post-injury period, and this process is inevitable. The damage level of this stage is very difficult to control, which depends on the intensity of force and the compression time on the spinal cord(DeVivo, Go, and Jackson, 2002). Therefore, we have no treatment for a primary mechanical injury.

A secondary injury mediated by multiple processes after the initial trauma(Amar and Levy, 1999). The time course of this process ranges from minutes to weeks following $\mathrm{SCl}$ and leads to further damage. The outcomes of $\mathrm{SCl}$ depend mainly on the extent of secondary damage produced by a series of cellular and molecular events such as inflammation(Popovich, Wei, and Stokes, 1997), free radical production(Hall, 1993, 1993), vascular events(Mautes et al., 2000), glutamate excitotoxicity(Dong and Wang, 1998), and apoptosis(Liu et al., 1997), which inevitably induce neuronal and glial cell death at and beyond the site of injury(Zhao et al., 2011).

The secondary stage can cause a series of events, for example, an inflammatory response induces higher extravasation of leukocytes and further tissue damage of the surrounding original injury site(Yang et al., 2005; Donnelly and Popovich, 2008).Moreover, several studies have demonstrated that inflammation also plays an important role in blocking neural tissue repair; free radical formation and lipid peroxidation cause oxidative death of the spinal cord neurons and reduce spinal cord blood flow that leads to edema and a continuation of the inflammatory response(Toborek et al., 1999); vascular changes lead to edema, necrosis, and ischemia(Bareyre and Schwab, 2003); glutamate excitotoxicity leads to further neuronal cell death; apoptosis can cause programmed cell death of neurons, oligodendrocytes, microglia, and, perhaps, astrocytes after SCl(Beattie, Farooqui, and Bresnahan, 2000). Moreover, this process will last for a long time(Wilson and Fehlings, 2014). Without immediate treatment, SCl will lead to neurological impairments in motor function, affect the function of brain regions, as well as the development of pain syndromes and mood disorders such as depression(Yiu and He, 2006). Therefore, 
developing novel therapeutic strategies for preventing this series of events of the secondary stage of $\mathrm{SCl}$ is highly prioritized.

\section{Flavonoids}

Flavonoids are in the most common and widely distributed group of plant phenolic compounds, occurring virtually in all plant parts, particularly the photosynthesizing plant cells. Meanwhile, flavonoids in food are generally responsible for colour, taste, prevention of fat oxidation, and protection of vitamins and enzymes.

Flavonoids are extracted from plants that have been used for the treatment of neurovascular and spinal diseases for centuries in Chinese medicine, and more experience is continuously gained about their significant neuroprotective properties(Sang et al., 2004; Lee et al., 2012; Wang et al., 1997; Zhao et al., 2006). Flavonoids are hydroxylated phenolic substances and are known to be synthesized by plants in response to microbial infection. A number of studies show flavonoids compounds have anti-inflammatory(Thao et al., 2016), antioxidant(Baharfar, Azimi, and Mohseni, 2015), anti-tumor(Srivastava et al., 2016; Saeed et al., 2015), anti-viral(Yin et al., 2014), anti-cardiovascular disease(Macready et al., 2014), and immunomodulatory effects(Sternberg et al., 2009).

Flavonoidscontaining a 2-phenyl chromone structure are common in nature(Tsuji et al., 2013). They make up a large group of polyphenolic compounds that have a benzo- $\psi$-pyrone structure and are ubiquitously present in plants. According to the oxidation degree of the structure of the three carbon bonds (C3) and the connection position of the B ring, the flavonoid compounds can be classified into the following categories (Fig 1):flavones, flavonol, isoflavone, chalcone, aurones, flavanes, anthocyanidins, biflavone and other two-hydrogen derivatives(Gonzales et al., 2015; Sternberg et al., 2009). Flavonoids occur as aglycones, glycosides, and methylated derivatives. The basic flavonoid structure is aglycone. The position of the benzenoid substituent divides the flavonoid class into flavonoids (2-position) and isoflavonoids (3-position). Flavonols differ from flavanones by a hydroxyl group at the3-position and aC2-C3 double bond(K.R.Narayana, 2001). Flavonoids are often hydroxylated in positions 3, 5, 7, and 2. When glycosides are formed, the glycosidic linkage is normally located in positions 3 or 7 and the carbohydrate can be L-rhamnose, D-glucose, glucorhamnose, galactose, or arabinose(Middleton, 1984).

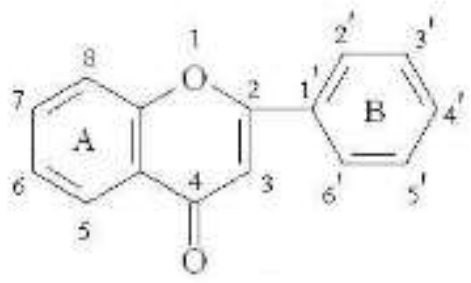

2-phenyl chromone

figure 1 The basic structure of flavonoids

Flavonoids have extensive biological properties thatpromote human health and help reduce the risk of diseases. The isoflavanglabridin, a major polyphenolic compound found in Glycyrrhiza glabra, inhibits low-density lipoprotein (LDL) oxidation via a mechanism involving scavenging of 
free radicals(Fuhrman et al., 1997). Flavonoids from Green or black tea may lower blood cholesterol concentrations and blood pressure, thereby providing some protection against cardiovascular disease. Flavonoids are also known to influence the quality and stability of foods by acting as antioxidants(Craig, 1999; Kumar et al., 2012). Flavonoids contained in berries may have a positive effect against Parkinson's disease and may help to improve memory in elderly people. Antihypertensive effect has been observed in hypertensive rats(Li et al., 2005).

\section{Pharmacology of flavonoids in SCl}

\section{Flavones and Dihydroflavones}

The key source of flavones and dihydroflavones (Fig2) is the Scutellaria baicalensis Georgi (Huang Qin),an important medicinal herb in China. It has been widely used for the treatment of inflammatory diseases and ischemic stroke for thousands of years. Baicalin (7-glucuronic acid, 5, 6-dihydroxyflavone,BC)(Fig2), a flavonoid compound isolated from Huang Qin, has been proven to possess anti-oxidant, anti-inflammatory, and anti-apoptotic properties. Importantly, BC can pass through the blood-brain barrier (BBB) into the central nervous system (CNS) and could be a novel and promising therapeutic agent for human spinal cord injury(Shang et al., 2006; Zhang et al., 2006; Gao et al., 1999).

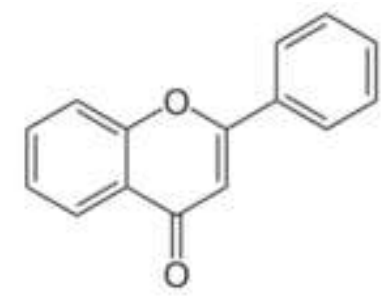

a

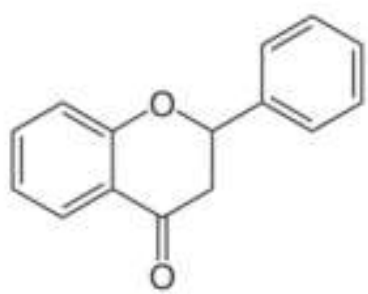

b

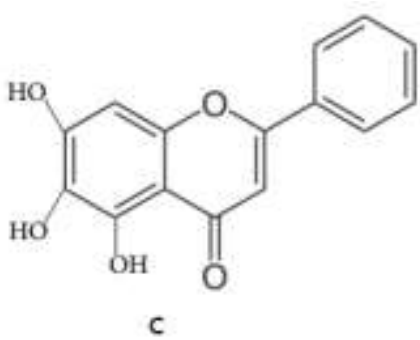

c

Fig 2 Structure of Flavones and Dihydroflavones: a. generic molecular structure of Flavones; b. generic molecular structure of Dihydroflavones; c. structure of Baicalin.

\section{Anti-inflammatory properties}

The inflammatory reaction within the spinal cord and generation of proinflammatory cytokines at the site of injury, such as tumor necrosis factor- $\alpha$ (TNF- $\alpha$ ) and nuclear factor-kB (NF-KB), has been shown to be involved in regulating the precise cellular events after $\mathrm{SCl}$ in a $\mathrm{SCl}$ rats model(Shang et al., 2006; Smith et al., 2010; Lin et al., 2010; Zhang et al., 2009). The generation of inflammatory cytokines is regulated by the transcription factor NF-KB in rat models with different cellular inflammatory reactions(Streit et al., 1998). It was found that by treatment with $\mathrm{BC}$, the expression of NF-KB mRNA and TNF- $\alpha$ mRNA significantly decreased, and the extent of spinal cord damage was also alleviated to some extent at the same time in a compression spinal cord injury rat model(Cao et al., 2010). Other studies found that intrathecalbaicalin significantly inhibited histone deacetylase 1 (HDAC1) phosphorylation in nerve ligation of rat spinal cords; which suggests that BC might directly affect the HDAC1 protein structure by modification at the posttranslational level to inhibit neuroinflammation in the spinal cord of rats with spinal nerve ligation(Cherng et al., 2014). Therefore, BC has helpful effects in treating the injured spinal cord. 


\section{Antioxidant properties}

It has been shown that production of free radicals and reactive oxygen species induced by $\mathrm{SCl}$ contribute to the disruption of endothelium and the opening of the blood-spinal cord barrier (BSCB), whereas anti-oxidant compounds attenuate edema formation and cell injury after $\mathrm{SCl}$ in rats(Sharma et al., 2006). BC is a scavenger of free radicals in cultured human neuroblastoma SH-SY5Y cells (Gao et al., 1999). The BC treatment significantly reduces the increased malonaldehyde(MDA) values and increases the glutathione (GSH) levels after $\mathrm{SCl}$ in an animal model, suggesting that the protective effect of $\mathrm{BC}$ may be related to the inhibition of free radical and oxidant formation.

\section{Anti-apoptotic properties}

Recent studies have demonstrated that BC possesses potent anti-apoptotic properties and attenuates cerebral ischemia injury in rats(Shang et al., 2006; and et al., 2010). Key anti-apoptotic signaling molecules in neurons are $\mathrm{Bcl}-2, \mathrm{Bax}$ and the Bcl-associated death promoter in transgenic mice(Martinou et al., 1994). BC reduces the expression of Bax and increases the expression of $\mathrm{Bcl}-2$ compared with $\mathrm{SCl}$ saline-treated rats. In addition, caspase-3 is activated during the early phase of apoptosis and activation of caspase- 3 is part of the apoptosis process by enhancing the cleavage of DNA, nuclear lamins, and cytoskeletal components. Taken together, these properties suggest that BC prevents the loss of anti-apoptotic signaling and reduces the pro-apoptotic pathway activation.

\section{Neuroprotective properties}

$\mathrm{SCl}$ results in a significant increase in lipid peroxidase, nitric oxide, TNF- $\alpha$, interleukin-1 $\beta$ (IL-1B), and Bax levels, whereas expression of bcl-2 and caspase- 3 are significantly reduced by treatment with chrysin. This shows that chrysin is a flavones containing antioxidant, and its anti-apoptotic property promotes the subsequent recovery of both motor and sensory functions via modulation of endogenous biomarkers and neuronal apoptosis to reduce the neurological deficits caused by $\mathrm{SCl}$ in a rat model of SCI(Kandhare et al., 2014).

\section{Flavonol and Dihydroflavonol}

Representative members of the flavonol and dihydroflavonol groups are rutin, quercetin, and Silymarin (Fig3). Rutin, a flavonoid obtained from plants, has been shown to be effective in conditions involving inflammation and oxidative stress. Studies show flavonoid compounds have anti-inflammatory, antioxidant, anti-tumor, anti-viral, anti-cardiovascular disease, and immunomodulatory effects(Matsunaga et al., 2000; Aruna et al., 2014; Song et al., 2015). Studies indicate that rutin improves spatial memory and neurological function in an Alzheimer's disease transgenic mouse model, and reduces neurodegeneration in the periphery of cortical injury(Xu et al., 2014; Rodrigues et al., 2013). A compound with anti-oxidative and anti-inflammatory properties such as quercetin is a potentially useful therapeutic treatment for $\mathrm{SCl}$. The experimental results also suggest a protective role for quercetin in the bladder against SCl-induced tissue damage by its ability to downregulate pro-inflammatory cytokines and to inhibit neutrophil infiltration and apoptosis, and to balance the oxidant-antioxidant status(Schultke et al., 2010). Silymarin, a European herbal drug, has been used for a long time by patients suffering from liver diseases of different etiology. Silymarin, purified from milk thistle 
silybummarianun, consists of a mixture of 7 flavonolignans and polyphenols. Silymarin has been identified in several in vitro and in vivo models as antioxidants and radical scavengers(Feher and Lengyel, 2012; Ramasamy and Agarwal, 2008).

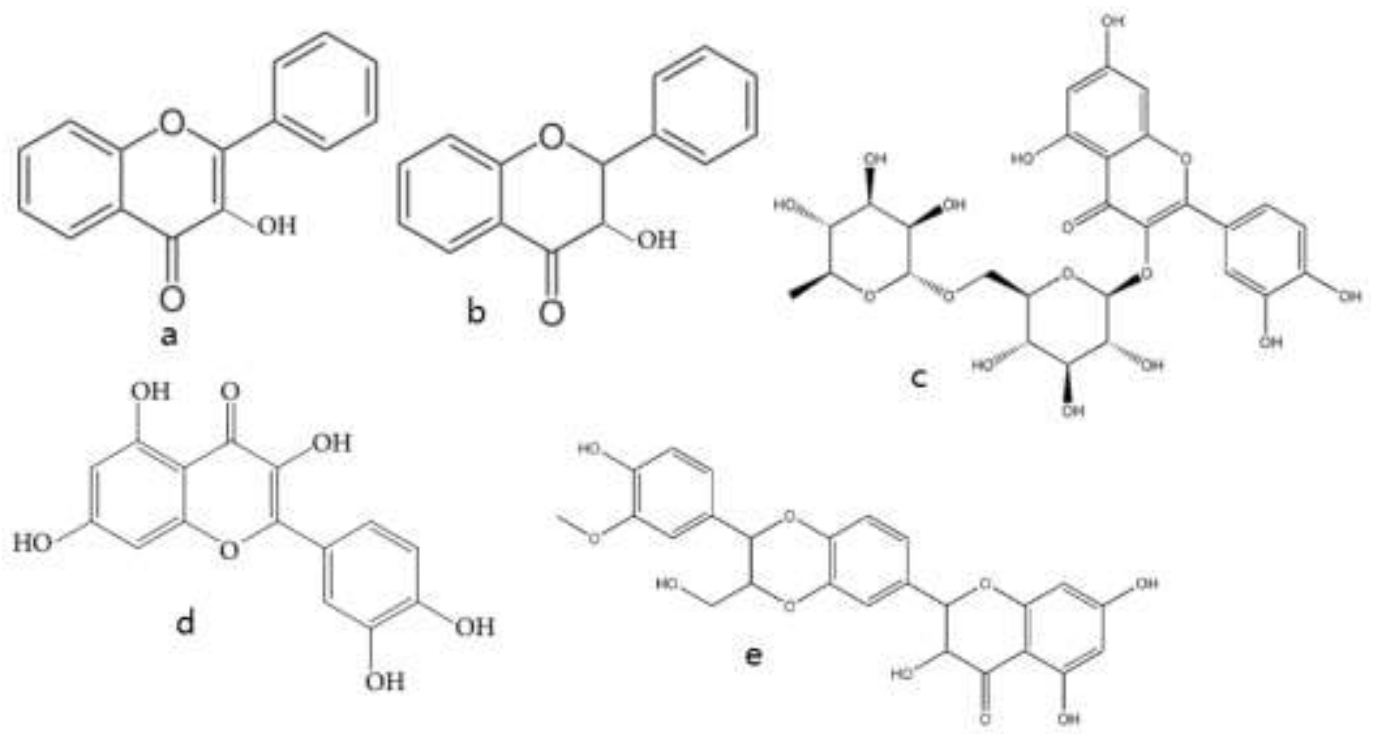

Fig3 Structure of Flavonol and Dihydroflavonol: a. generic molecular structure of Flavonol; b. molecular structure of Dihydroflavonol; c. structure of rutin; d. structure of quercetin; e. structure of Silymarin.

\section{Anti-inflammatory properties}

Studies show that rutin suppresses NLRP3 (NACHT, LRR, and PYD domains-containing protein 3) inflammasome activation and decreases levels of IL-1 $\beta$, IL-18, TNF- $\alpha$ and reduces ROS and MDA productions by histopathology at the $72 \mathrm{~h}$ after $\mathrm{SCl}$ in a rat model(Zendedel et al., 2016). Quercetin has been shown to reduce plasma levels of pro-inflammatory cytokines (TNF- $\alpha$, IL-6, IL-1 $\beta$ ), myeloperoxidase (MPO) levels, and ameliorates nano zinc oxide particle-induced nephrotoxicity in rats after SCl in an animal model(Impellizzeri et al., 2015; Schultke, Griebel, and Juurlink, 2010).

\section{Anti-oxidative properties}

Studies showed that rutin control oxidative stress by inhibition of NLRP3 oxidant activation in a rat model of SCI(Wu et al., 2016; Schroder and Tschopp, 2010). This indicates that the activation of the Protein 38 mitogen-activated protein kinase/inducible nitric oxide synthase (p38MAPK/iNOS)signaling pathway is involved in the secondary injury mechanism post-SCI(Lawrence et al., 2008), quercetin can regulate secondary oxidative stress following SCl by directly clearing oxidants and inhibiting activation of thep38MAPK/iNOS pathway in $\mathrm{SCl}$ rats(Wu et al., 2016). In another study, investigators treated mixed neuronal/glial cell cultures with Silymarin. The results show that Silymarin inhibits cell proliferation and protects mixed glial cell cultures against peroxide toxicity. Protein kinase C (PKC) or NF-kB inhibitors blocked Silymarin protection against $\mathrm{H}_{2} \mathrm{O}_{2}$ toxicity. Silymarin protected mixed cortical and spinal neuronal/glial cells against peroxide challenge, spinal cord neuronal/glial cell cultures from lipopolysaccharides (LPS)induced inflammation, and glial cell cultures and microglia from LPS stimulation or peroxide toxicity in primary neuronal/glial cell cultures and in vivo(Tsai et al., 2010). 


\section{Anti-apoptotic properties}

In addition, rutin can prevent $\mathrm{SCl}$-induced programmed cell death in $\mathrm{SCl}$ rats model (Zhang and $\mathrm{Ma}, 2015)$. A study revealed that rutin reduced programmed cell death by influencing the down-regulation of the NLRP3 in an alcohol and cerulein-induced rat model of pancreatitis(Aruna, Geetha, and Suguna, 2014). Jeong et al. reported that rutin inhibited myocardial ischemia/reperfusion-induced apoptosis via extracellular regulated protein kinases 1/2 (ERK1/2) and phosphatidylinositol 3 kinase/ protein kinase B (PI3K/Akt) signaling in vitro(Jeong et al., 2009). Caspase 3 has been associated with apoptosis in spinal cord injury, and quercetin treatment counteracted apoptotic cell death as measured by immunoblotting of the cleaved caspase 3 and caspase 3 activity. Moreover, quercetin inhibited the phosphorylation of the c-Jun $\mathrm{N}$-terminal kinase/stress-activated protein kinase in rats(Wei et al., 2012; Dasari et al., 2007) (JNK/SAPK)and p38MAPK that are involved in the inhibition of cell growth as well as the induction of apoptosis in an animal model(Angeloni and Hrelia, 2012; Cevik et al., 2013).

\section{Neuroprotective properties}

Rutin exhibits neuroprotective effects through antioxidative and anti-inflammatory activity. In vitro, rutin reduces nitric oxide and pro-inflammatory cytokine production in SH-SY5Y neuroblastoma cells(Wang, Wang, et al., 2012). Furthermore, rutin attenuated 6-hydroxydopamine-induced neurotoxicity via improving antioxidant enzyme levels and reducing lipid peroxidation in PC-12 cells(Magalingam, Radhakrishnan, and Haleagrahara, 2013). Moreover, in vivo, rutin has been demonstrated to enhance the neurotrophic effect by reduction of macrophage inflammatory protein-2 (MIP-2) and p-Akt expression and matrix metallopeptidase-9activation in SCl rats(Zhang and $\mathrm{Ma}$, 2015). Furthermore, rutin augments Basso Beattie Bresnahan scores and decreased spinal cord water content of $\mathrm{SCl}$ rats. Following quercetin treatment of $0.2 \mathrm{mg} / \mathrm{kg}$ per day, the mean values of motor activity scores and critical angle of inclined plane test were significantly increased that even brief exposure to quercetin had some neuroprotective effect in an animal model of spinal cord compression injury(Schultke et al., 2010).

\section{Isoflavone and Dihydroisoflavone}

A representative member of the Isoflavone and Dihydroisoflavone group is Puerarin (Fig4). Puerarinis extracted from Radix puerariae that has been used for the treatment of neurovascular and spinal diseases for centuries in Chinese medicine, and its significant neuroprotective properties have attracted attention, particularly in the treatment of spinal ischemic damage(Sang et al., 2004; Xing et al., 2011). Available reports on the neuroprotective mechanisms of puerarin involve superoxide dismutase activity(Nwose and Ewing, 2009), lipidperoxidation, fibrinolysis, inflammatory responses, and cell apoptosis(Xu et al., 2005). 
<smiles>O=c1c(-c2ccccc2)coc2ccccc12</smiles>

a<smiles>O=C1c2ccccc2OCC1c1ccccc1</smiles>

b<smiles></smiles>

Fig 4 Structure of Isoflavone and Dihydroisoflavone: a. the generic molecular structure of Isoflavone; b. the generic molecular structure of Dihydroisoflavone; c. structure of Puerarin.

\section{Neuroprotective properties}

Previous studies have shown a neuroprotective effect of puerarin on spinal ischemic damage in an animal model. Furthermore, puerarin can also increase spinal blood flow in Clinical observation(Zhou et al., 2006), and reduce spinal cord injury in an ischemia-reperfusion rabbit model. A recent study has demonstrated that puerarin reduces hypoxia inducible factor 1 and TNF- $\alpha$ levels, apoptosis, and neutrophil activation, resulting in a reduction of the infarct volume in ischemia-reperfusion brain injury in rats(Chang et al., 2009). The neuroprotective mechanism of puerarin against spinal ischemia-reperfusion injury may involve the upregulation of thioredoxin mRNA and reduction of apoptosis in the spinal cord ischemia-reperfusion injury rat model(Tian et al., 2011). The neurological deficit caused by $\mathrm{SCl}$ / reperfusion injury (RI) was associated with glutamate release and elevation of glutamate RNA expression in acute spinal cord injury rat model(Tian, Xu, et al., 2013).

\section{Chalcone}

The representative member of the chalcone group is Safflower Yellow (SY; Fig5), which is extracted from the flowers of the plant safflower (Carthamus tinctorius) and in traditional Chinese medicine it has been extensively used for the treatment of cardio-cerebrovascular diseases. Hydroxysafflor yellow A (HSYA) (Fig5), which is the main chemical component of the safflower yellow pigments, has been demonstrated to have potent antioxidative effect in vitro(Jin, $\mathrm{Li}$, and $\mathrm{Wu}, 2004)$. SY can promote blood circulation, remove blood stasis, and thereby improve capillary circulation at the site of tissue injury. Additionally, a previous study indicated that SY alleviates the injured tendon adhesion and inflammatory reaction and promotes the repair of injured tendons(Shan et al., 2010). Recent studies revealed that HSYA could alleviate ischemia-reperfusion injury of the lung, heart and brain via scavenging of free radicals(He et al., 2008; Wei et al., 2005). 


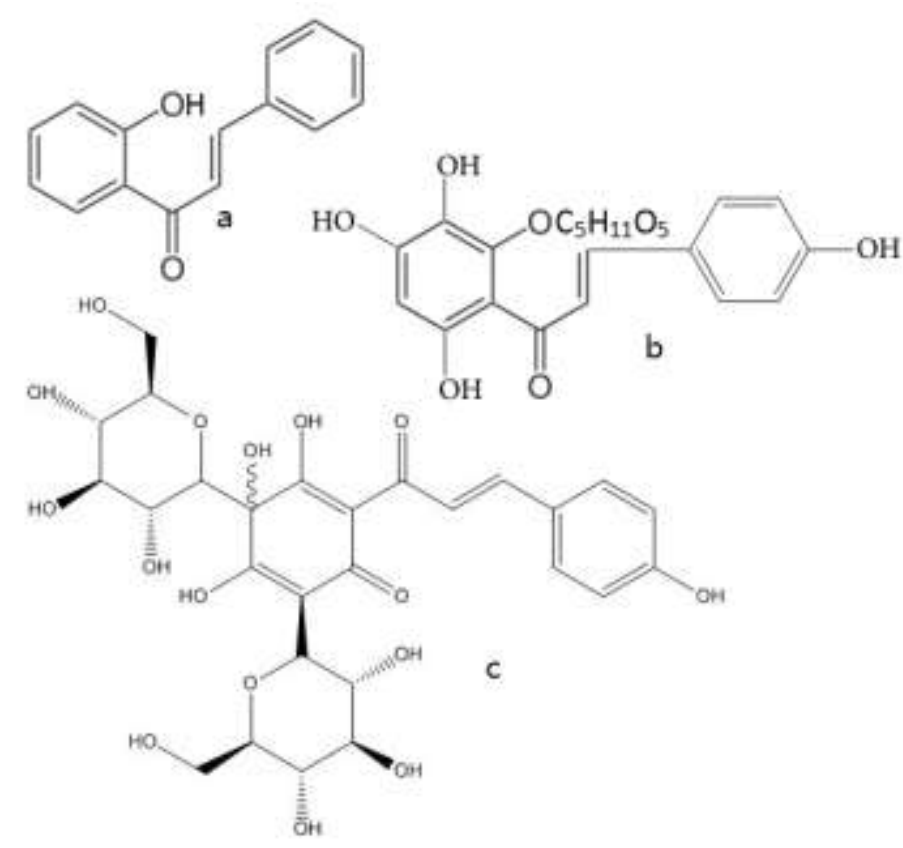

Fig 5 Structure of chalcone: a. the generic molecular structure of chalcone; b. structure of Safflower yellow (SY); c. structure of Hydroxysafflor yellow A (HSYA).

\section{Anti-inflammatory properties}

IL-8 is an important cytokine, which plays a key role in the inflammation response(Kunihara et al., 2000). One study shows that SYinhibits IL-8 expression and the inflammatory response induced by SCIRI in a rabbit spinal cord ischemia reperfusion(IR) injury animal model(Zhou et al., 2013).

\section{Antioxidant properties}

Safflower and its extracts play an important role in of inhibiting lipid peroxidation and clearing oxygen free radicals in rats(Ma et al., 2015). Safflower injection can significantly activate glutathione peroxidase and superoxide Dismutase (SOD) and decrease MDA levels in myocardium ischemia reperfusion injury. These results indicate that SY could play an important role in spinal cord protection by relieving lipid peroxidation in a rabbit spinal cord ischemia reperfusion injury animal model(Zhou et al., 2013).

\section{Anti-apoptotic properties}

A recent study confirmed that activation of caspase-3 expression correlates with levels of cell apoptosis after $\mathrm{SCl}$, suggesting that caspase-3 could be used as biochemical index in assessing post-ischemic spinal cord injury in the clinic(Lin et al., 2012). The results demonstrate that inhibiting caspase-3 expression may represent a mechanism by which SY confers protection against $\mathrm{SCl}$ in a rabbit spinal cord ischemia reperfusion injury animal model(Zhou et al., 2013). HSYA significantly reduced the number of apoptotic cells in the anterior horn of the spinal cord. This protective effect of HSYA against neuronal apoptosis may be related to its antioxidative effect because a major mechanism of ischemia/reperfusion induced apoptosis is attributed to ROS release in a rabbit spinal cord ischemia reperfusion injury animal model (Shan et al., 2010). 


\section{Neuroprotective properties}

One study provided direct in vivo evidence that HSYA confers neuroprotection through its antioxidative action. Moreover, the neuroprotective effect of HSYA might also be attributed to its inhibition of thrombosis formation and platelet aggregation, its regulation of the prostaglandin 12/thromboxane ratio and blood rheological changes, as well as its suppression of inflammatory responses in a ischemic injury rat model(Zhu et al., 2005; Ye and Gao, 2008).

\section{Flavanes}

A typical flavane is the (-)-Epigallocatechingallate (EGCG) (Fig6), the most abundant active component of the tea catechins and thought to be responsible for most of the biological activity of green tea extracts(Kimura et al., 2002). EGCG is known for its potent antioxidant and anti-inflammatory properties(Kim et al., 2003). EGCG also has been shown to have some protective effects against neuronal damage. A recent study shows that EGCG could attenuate neuronal apoptosis and improve locomotor function after $\mathrm{SCl}$ in rats(Khalatbary and Ahmadvand, 2011).<smiles>c1ccc(C2CCc3ccccc3O2)cc1</smiles>

a<smiles>O=C(O[C@H]1Cc2c(O)cc(O)cc2O[C@@H]1c1cc(O)c(O)c(O)c1)c1cc(O)c(O)c(O)c1</smiles>

Fig 6Structure of flavane: a. the generic molecular structure of flavane; $b$. structure of (-)-Epigallocatechingallate (EGCG).

\section{Anti-inflammatory properties}

A recent study showed that MPO activity significantly decreased in EGCG-treatment groups. Attenuated TNF- $\alpha$, IL-1 $\beta$, Nitrotyrosine, iNOS, cyclooxygenase-2 (COX-2), and poly-ADP-ribose polymerase (PARP) expression was obseved in the EGCG treated rats. Also, EGCG attenuated myelin degradation. It appears that EGCG may be effective in protecting rat spinal cord neurons from secondary damage by modulating the inflammatory response in a spinal cord trauma rat model(Khalatbary and Ahmadvand, 2011).

\section{Antioxidant properties}

Another study showed that EGCG modulates the levels of $\mathrm{O}^{2-}$ and SOD. In addition, the MDA levels in the EGCG treatment groups were significantly lower than those in the trauma group after SCI in an SCI rat model(F. Deng, 2011; Khalatbary et al., 2010).

\section{Anti-edema properties}

The results of a different study imply that EGCG has an anti-edema effect after acute SCI. 
The anti-edema effect could be the result of down-regulation of the expression of Aquaporin-4 (AQP4) protein levels. Also EGCG may reduce astrogliosis after $\mathrm{SCl}$ through down-regulation the expression of glial fibrillary acidic protein (GFAP) levels in a SCl rat model(Ge et al., 2013).

\section{Anti-apoptotic properties}

EGCG inhibits the expression of the pro-apoptotic protein Bax and increases that of the anti-apoptotic protein Bcl-2, thereby providing a molecular mechanism for the neuroprotective activity of EGCG. The number of TUNEL-positive cells at the spinal lesion site of EGCG-treated rats was significantly lower than that in the trauma group in the contusive spinal cord injury rat model(Khalatbary et al., 2010).

\section{Neuroprotective properties}

Intravenous infusion of EGCG in acute or chronic phase following $\mathrm{SCl}$ in rats promotes significant locomotor recovery as measured by the standard motor tests and The Louisville Swim Scale tests. EGCG-treated SCI animals significantly improve on the tactile allodynia reflex and mechanical nociception threshold(Renno et al., 2014). Moreover, 4 weeks after SCl, the expression of neurotrophic factors BDNF and GDNF in the spinal cords of EGCG-treated animals were higher than in the control group(Tian, Han, et al., 2013). Treatment with EGCG modulates the expression of growth associated protein-43 (GAP-43) and GFAP levels and protects neurons from degeneration caused by contusion lesion in the spinal cord in rats(Renno et al., 2014).

\section{Anthocyanidins}

Anthocyanins (Fig7) are natural pigments belonging to the flavonoid family and are present in fruits and vegetables. They are known to have powerful antioxidant effects, anti-carcinogenic properties and potent cardioprotective effects. They can also inhibit inflammation(Romero et al., 2008; Steed and Truong, 2008; Xu and Chang, 2009). Among anthocyanins, cyanidin 3-O- $\beta$-glucoside (C3G) (Fig7) has the highest protective effects as a scavenger of active oxygen species in hepatic ischemia-reperfusion damage and cerebral ischemia models. Two studies were published on the pre-/post-treatment of C3G which showed significant improvement of neurological recovery and a decrease of infarction volume in cerebral ischemia rat models(Kang et al., 2006; Shin, Park, and Kim, 2006). Bog bilberry is a low-growing deciduous shrub of the Ericaceae family of plants. Berries of the Ericaceae family are known to contain organic acids, vitamins, glycosides, and anthocyanins and have been reported to have antioxidant activity. Bog bilberry anthocyanin extract (BBAE) (Fig7)has been shown to have antioxidant activity(Kim et al., 2009).<smiles>Oc1cc(O)c2cc(O)c(-c3ccc(O)c(O)c3)[o+]c2c1</smiles>
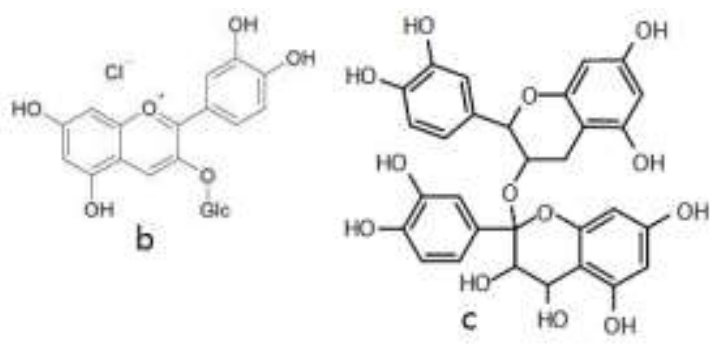

Fig 7 Structure of Anthocyanins: a. generic molecular structure of Anthocyanins; b. structure 
of cyanidin 3-O- $\beta$-glucoside (C3G); c. structure of Bog bilberry anthocyanin extract (BBAE).

\section{Anti-inflammatory properties}

BBAE treatment reduced the expression the key cytokines TNF-a, IL-1 1 , and IL- 6 in a rat model of SCI(Wang, Ma, et al., 2012).

\section{Antioxidant properties}

The main therapeutic role of C3G is the scavenger of ROS. C3G significantly reduced the production of superoxides in lesion peripheries of $\mathrm{SCl}$ in the traumatic $\mathrm{SCl}$ rat model(Kim et al., 2011).

\section{Neuroprotective properties}

In addition, C3G decreased the lesion volume and protected motor neurons in the anterior horn of lesion peripheries 14 days after SCl in rats(Kim et al., 2011).These observations show that the BBAE therapy could exert protective effect on the neurons and promotes neuronal survival after $\mathrm{SCl}$. In addition, BBAE can reduce myelin axonal loss, glial scars formation, and astrocyte proliferation after $\mathrm{SCl}$ in a rat model(Wang, $\mathrm{Ma}$, et al., 2012).

\section{Biflavone}

A representative member of the biflavonoid group (Fig 8) is the Ginkgo biloba extract (EGb761), a complex mixture of ingredients with broad pharmacological effects on the CNS. Recent studies using the $\mathrm{SCl}$ model revealed that EGb761 is involved in the protection of spinal cord neurons in ischemic injury in vivo(Mechirova et al., 2009) and hydrogen peroxide-induced spinal cord neuronal death in vitro. The neuroprotective effects of EGb761 include scavenging free radicals, lowering oxidative stress, reducing neural damage, preventing platelet aggregation, and anti-inflammation(Wang, Ma, et al., 2012; Jiang et al., 2009; Kotakadi et al., 2008). Ginkgolides $B$ is the active constituent that has attracted the most attention in recent years. Ginkgolide B can improve hemorrhage, edema, necrosis, and inflammatory cell infiltrates in the injured spinal cord(Zhang et al., 2016).<smiles>[Z2]c1cc(OC)cc2oc(-c3ccc(OC)c(-c4c(O)cc(O)c5c(=O)cc(-c6ccc(O)cc6)oc45)c3)cc(=O)c12</smiles>

Fig 8 Structure of biflavonoid: a. generic molecular structure of biflavonoid; b. structure of Ginkgo biloba extract (EGb761); c. structure of ginkgolides B.

\section{Antioxidant properties}

Ginkgo biloba extract (GBE) ameliorated the down-regulation of SOD and produced a significant reduction of MDA levels in spinal cord ischemia/reperfusion rabbits(Fan, Wang, and Cheng, 2006). MP and Ginkgo biloba treatments significantly decreased MDA levels. Furthermore, MP and Ginkgo biloba has a protective effect against ischaemic spinal cord injury via their 
antioxidant effects in rat model(Koc et al., 1995). The research demonstrated that iNOS expression was upregulated after $\mathrm{SCl}$. EGb761 can suppress iNOS expression and prevent neuronal death in $\mathrm{SCl}$ rats(Ao et al., 2006).

\section{Anti-apoptotic properties}

GBE was able to reduce the number of apoptotic cells, demonstrating its ability to reduce apoptosis. Levels of bcl-2 were up-regulated by GBE. The up-regulation of Bax was greatly diminished by GBE in rabbits). Analysis of apoptosis results and caspase- 3 staining demonstrats that cell apoptosis was increased at 1-14 days post injury (DPI). At $7 \mathrm{DPI}$, the quantity of apoptotic cells significantly decreased in the EGb761-treated group in rats with acute spinal cord contusion injury(Yan et al., 2016). GBE inhibited nerve cell apoptosis via the mitochondrial caspase-dependent and caspase-independent pathways after spinal cord ischemia-reperfusion in rabbits. Furthermore, GBE could reduce levels of caspase- 9 and apoptosis-inducing factor in the cytoplasm and serum(Cheng et al., 2011).

\section{Neuroprotective properties}

In a spinal cord ischemia/reperfusion study in rabbits, GBE improved the motor score and reduced lipid peroxidation and apoptosis(Fan, Wang, and Cheng, 2006). EGb761 protected spinal cord neurons against these insults indicating that such protection is mediated, at least in part, through the inhibition of cytosolic phospholipase A2 (CPLA2). The ERK1/2 signaling pathway mediated the activation of CPLA2, and treatment with EGb761 significantly decreased ERK1/2 phosphorylation. Thus, EGb761 may be considered as a potential therapeutic agent aiming at reducing secondary degeneration(Zhao et al., 2011).

\section{Conclusion and future studies}

In this paper, we reviewed therapeutic effects of different kinds of flavonoids (Fig 9), which mainly have anti-inflammatory, antioxidant, anti apoptosis and neuroprotective properties in treatment of $\mathrm{SCl}$. The anti-inflammatory properties are mainly due to inhibiting the production of inflammatory cytokines. Flavonoids can reduce expression of NF-KB mRNA and TNF- $\alpha$ mRNA and decrease of IL-1 $\beta, I L-8, I L-18$, and TNF- $\alpha$ levels. The antioxidative property of flavanoids in $\mathrm{SCl}$ is through reducing ROS, MDA, and iNOS activity, increasing the GSH levels, and blocking $\mathrm{H}_{2} \mathrm{O}_{2}$ toxicity and LPS stimulation. The anti-edema effect of flavanoid treatment after acute $\mathrm{SCl}$ is via down-regulation of the expression of AQP4 protein and GFAP proteins. Anti-apoptotic properties act mainly through the reduction of the expression of Bax, increase of the expression of Bcl-2 levels, and inhibition of caspase-3 expression and caspase- 3 activity. Neuroprotective properties of the flavanoids after $\mathrm{SCl}$ work by reducing myelin axonal loss, glial scars formation, and astrocyte proliferation after $\mathrm{SCl}$. Moreover, flavanoids could increase neurotrophic factors BDNF and GDNF in the spinal cords and decrease deactivationof growth signaling pathways.

Spinal cord injury may lead to neurological complications and eventually to paraplegia or quadriplegia. However, there is no effective treatment available, the main reason may be the complex pathophysiological mechanisms of spinal cord injury, and the secondary damage induced by a series of cellular and molecular events. Fortunately, flavonoids show promising therapeutic potential in spinal cord injury. Nevertheless, the molecular mechanisms involved in 
TCM treatments still remain unclear, which require further research to reveal these. We hope that the TCM treatment combined with other treatments can treat and repair spinal cord injury in the near future, bringing key benefits to patients.

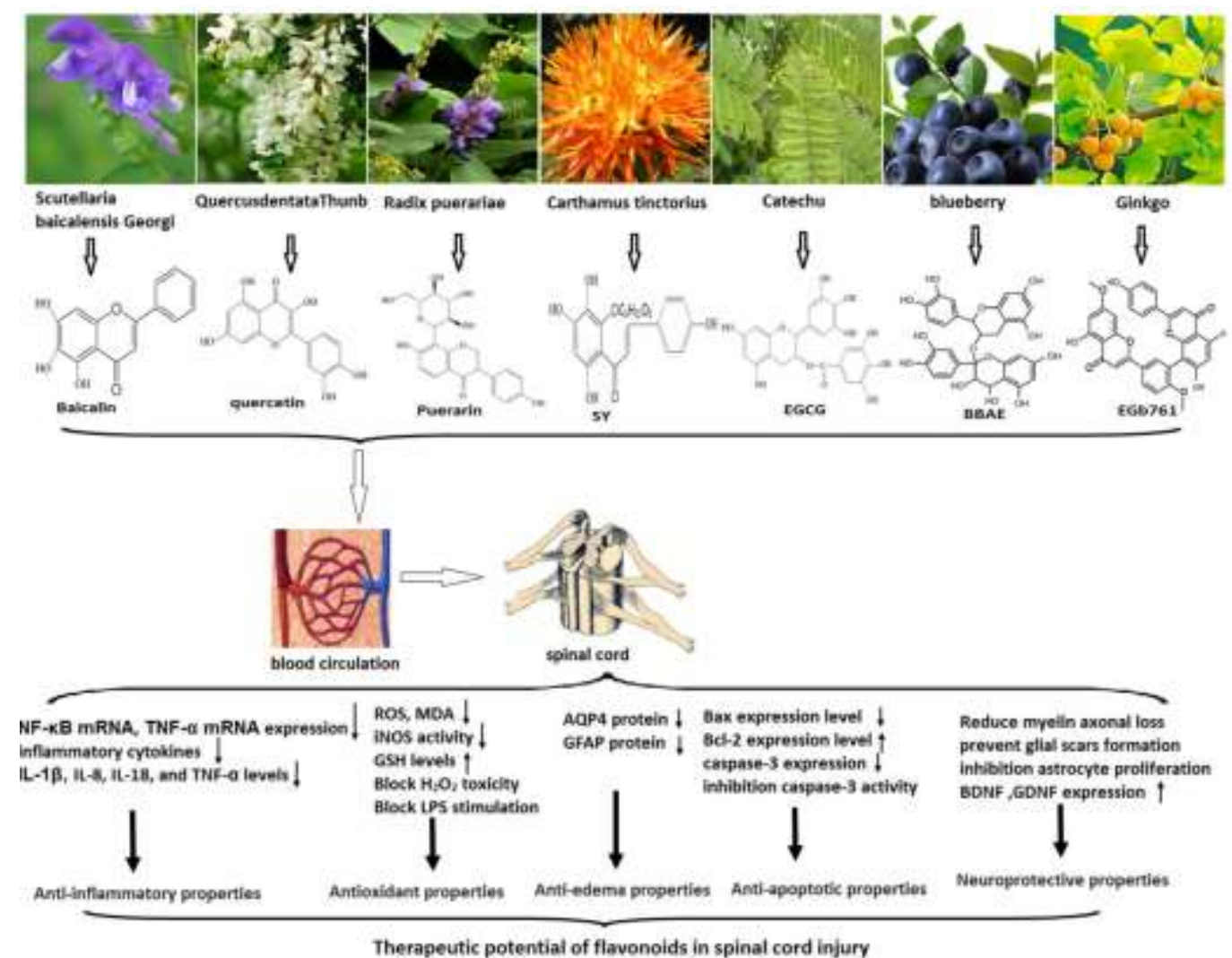

\section{Acknowledgment}

All authors declare that they have no competing interests. 


\section{References:}

Abbaszadeh, H. A. Tiraihi T. Noori-Zadeh A. Delshad A. R. Sadeghizade M. and Taheri T., (2015). Human ciliary neurotrophic factor-overexpressing stable bone marrow stromal cells in the treatment of a rat model of traumatic spinal cord injury. CYTOTHERAPY 17,912-921.

Ahuja, C. S. Martin A. R. and Fehlings M., (2016). Recent advances in managing a spinal cord injury secondary to trauma. F1000Res 5,1017.

Amar, A. P. and Levy M. L., (1999). Pathogenesis and pharmacological strategies for mitigating secondary damage in acute spinal cord injury. NEUROSURGERY 44,1027-1039; discussion 1039-1040.

Angeloni, C. and Hrelia S., (2012). Quercetin reduces inflammatory responses in LPS-stimulated cardiomyoblasts. Oxidative Medicine and Cellular Longevity 2012,837104.

Ao, Q. Sun X. H. Wang A. J. Fu P. F. Gong K. Zuo H. C. Gong Y. D. and Zhang X. F., (2006). Protective effects of extract of Ginkgo biloba (EGb 761) on nerve cells after spinal cord injury in rats. SPINAL CORD 44,662-667.

Aras, M. Altas M. Motor S. Dokuyucu R. Yilmaz A. Ozgiray E. Seraslan Y. and Yilmaz N., (2015). Protective effects of minocycline on experimental spinal cord injury in rats. INJURY-INTERNATIONAL JOURNAL OF THE CARE OF THE INJURED 46,1471-1474.

Aruna, R. Geetha A. and Suguna P., (2014). Rutin modulates ASC expression in NLRP3 inflammasome: a study in alcohol and cerulein-induced rat model of pancreatitis. MOLECULAR AND CELLULAR BIOCHEMISTRY 396,269-280.

Aruna, R. Geetha A. Suguna P. and Suganya V., (2014). Rutin rich Emblica officinalis Geart. fruit extract ameliorates inflammation in the pancreas of rats subjected to alcohol and cerulein administration. J Complement Integr Med 11,9-18.

Baharfar, R. Azimi R. and Mohseni M., (2015). Antioxidant and antibacterial activity of flavonoid-, polyphenol- and anthocyanin-rich extracts from Thymus kotschyanus boiss \& hohen aerial parts. J Food Sci Technol 52,6777-6783.

Bareyre, F. M. and Schwab M. E., (2003). Inflammation, degeneration and regeneration in the injured spinal cord: insights from DNA microarrays. TRENDS IN NEUROSCIENCES 26,555-563.

Beattie, M. S. Farooqui A. A. and Bresnahan J. C., (2000). Review of current evidence for apoptosis after spinal cord injury. J Neurotrauma 17,915-925.

Boots, A. W. Haenen G. R. and Bast A., (2008). Health effects of quercetin: from antioxidant to nutraceutical. EUROPEAN JOURNAL OF PHARMACOLOGY 585,325-337.

Cao, Y. Li G. Wang Y. F. Fan Z. K. Yu D. S. Wang Z. D. and Bi Y. L., (2010). Neuroprotective effect of baicalin on compression spinal cord injury in rats. BRAIN RESEARCH 1357,115-123.

Cevik, O. Ersahin M. Sener T. E. Tinay I. Tarcan T. Cetinel S. Sener A. Toklu H. Z. and Sener G., (2013). Beneficial effects of quercetin on rat urinary bladder after spinal cord injury. JOURNAL OF SURGICAL RESEARCH 183,695-703.

Chang, Y. Hsieh C. Y. Peng Z. A. Yen T. L. Hsiao G. Chou D. S. Chen C. M. and Sheu J. R., (2009). Neuroprotective mechanisms of puerarin in middle cerebral artery occlusion-induced brain infarction in rats. JOURNAL OF BIOMEDICAL SCIENCE 16,9.

Cheng, B. Wang W. Lin L. Li F. and Wang X., (2011). The change of the spinal cord ischemia-reperfusion injury in mitochondrial passway and the effect of the Ginkgo biloba extract's preconditioning intervention. CELLULAR AND MOLECULAR NEUROBIOLOGY 31,415-420. 
Cheng, I. Githens M. Smith R. L. Johnston T. R. Park D. Y. Stauff M. P. Salari N. Tileston K. R. and Kharazi A. I., (2016). Local versus distal transplantation of human neural stem cells following chronic spinal cord injury. Spine Journal 16,764-769.

Cherng, C. H. Lee K. C. Chien C. C. Chou K. Y. Cheng Y. C. Hsin S. T. Lee S. O. Shen C. H. Tsai R. Y. and Wong C. S., (2014). Baicalin ameliorates neuropathic pain by suppressing HDAC1 expression in the spinal cord of spinal nerve ligation rats. JOURNAL OF THE FORMOSAN MEDICAL ASSOCIATION 113,513-520.

Chinnock, P. and Roberts I., (2005). Gangliosides for acute spinal cord injury. Cochrane Database Syst Rev,CD004444.

Chou, A. K. Yang M. C. Tsai H. P. Chai C. Y. Tai M. H. Kwan A. L. and Hong Y. R., (2014). Adenoviral-mediated glial cell line-derived neurotrophic factor gene transfer has a protective effect on sciatic nerve following constriction-induced spinal cord injury. PLoS One 9,e92264.

Craig, W. J., (1999). Health-promoting properties of common herbs. AMERICAN JOURNAL OF CLINICAL NUTRITION 70,491S-499S.

Dasari, V. R. Spomar D. G. Cady C. Gujrati M. Rao J. S. and Dinh D. H., (2007). Mesenchymal stem cells from rat bone marrow downregulate caspase-3-mediated apoptotic pathway after spinal cord injury in rats. NEUROCHEMICAL RESEARCH 32,2080-2093.

DeVivo, M. J. Go B. K. and Jackson A. B., (2002). Overview of the national spinal cord injury statistical center database. JOURNAL OF SPINAL CORD MEDICINE 25,335-338.

Dong, L. P. and Wang T. Y., (1998). Effects of puerarin against glutamate excitotoxicity on cultured mouse cerebral cortical neurons. Zhongguo Yao Li Xue Bao 19,339-342.

Donnelly, D. J. and Popovich P. G., (2008). Inflammation and its role in neuroprotection, axonal regeneration and functional recovery after spinal cord injury. EXPERIMENTAL NEUROLOGY 209,378-388.

Evaniew, N. Noonan V. K. Fallah N. Kwon B. K. Rivers C. S. Ahn H. Bailey C. S. Christie S. D. Fourney D. R. Hurlbert R. J. Linassi A. G. Fehlings M. G. Dvorak M. F. and Network Rhscir. (2015). Methylprednisolone for the Treatment of Patients with Acute Spinal Cord Injuries: A Propensity Score-Matched Cohort Study from a Canadian Multi-Center Spinal Cord Injury Registry. J Neurotrauma 32,1674-1683.

F. Deng, R. Li, Y. Yang, D. Zhou, Q. Wang, J. Xu. (2011). Neuroprotective effect of epigallocatechin-3-gallate on hemisectioninduced spinal cord injury in rats. NEURAL REGENERATION RESEARCH 6,405-411.

Fan, L. H. Wang K. Z. and Cheng B., (2006). Effects of Ginkgo biloba extract on lipid peroxidation and apoptosis after spinal cord ischemia/reperfusion in rabbits. Chin J Traumatol 9,77-81.

Feher, J. and Lengyel G., (2012). Silymarin in the prevention and treatment of liver diseases and primary liver cancer. Curr Pharm Biotechnol 13,210-217.

Fuhrman, B. Buch S. Vaya J. Belinky P. A. Coleman R. Hayek T. and Aviram M., (1997). Licorice extract and its major polyphenol glabridin protect low-density lipoprotein against lipid peroxidation: in vitro and ex vivo studies in humans and in atherosclerotic apolipoprotein E-deficient mice. AMERICAN JOURNAL OF CLINICAL NUTRITION 66,267-275.

Gao, Z. Huang K. Yang X. and Xu H., (1999). Free radical scavenging and antioxidant activities of flavonoids extracted from the radix of Scutellaria baicalensis Georgi. Biochim Biophys Acta 1472,643-650.

Ge, R. Zhu Y. Diao Y. Tao L. Yuan W. and Xiong X. C., (2013). Anti-edema effect of epigallocatechin 
gallate on spinal cord injury in rats. BRAIN RESEARCH 1527,40-46.

Gonzales, G. B. Smagghe G. Grootaert C. Zotti M. Raes K. and Van Camp J., (2015). Flavonoid interactions during digestion, absorption, distribution and metabolism: a sequential structure-activity/property relationship-based approach in the study of bioavailability and bioactivity. DRUG METABOLISM REVIEWS 47,175-190.

Hall, E. D., (1993). Lipid antioxidants in acute central nervous system injury. ANNALS OF EMERGENCY MEDICINE 22,1022-1027.

- _ (1993). The role of oxygen radicals in traumatic injury: clinical implications. JOURNAL OF EMERGENCY MEDICINE 11 Supp/ 1,31-36.

Hanna, A. Thompson D. L. Hellenbrand D. J. Lee J. S. Madura C. J. Wesley M. G. Dillon N. J. Sharma T. Enright C. J. and Murphy W. L., (2016). Sustained release of neurotrophin-3 via calcium phosphate-coated sutures promotes axonal regeneration after spinal cord injury. JOURNAL OF NEUROSCIENCE RESEARCH 94,645-652

He, H. Yang X. Shi M. Zeng X. Yang J. Wu L. and Li L., (2008). Protective effects of hydroxysafflor yellow $A$ on acute and chronic congestive cardiac failure mediated by reducing ET-1, NOS and oxidative stress in rats. JOURNAL OF PHARMACY AND PHARMACOLOGY 60,115-123.

Hurlbert, R. J., (2014). Methylprednisolone for the treatment of acute spinal cord injury: point. NEUROSURGERY 61 Suppl 1,32-35.

Hurlbert, R. J. Hadley M. N. Walters B. C. Aarabi B. Dhall S. S. Gelb D. E. Rozzelle C. J. Ryken T. C. and Theodore N., (2015). Pharmacological therapy for acute spinal cord injury. NEUROSURGERY 76 Suppl 1,S71-83.

Impellizzeri, D. Talero E. Siracusa R. Alcaide A. Cordaro M. Maria Zubelia J. Bruschetta G. Crupi R. Esposito E. Cuzzocrea S. and Motilva V., (2015). Protective effect of polyphenols in an inflammatory process associated with experimental pulmonary fibrosis in mice. $\mathrm{Br} \mathrm{J} \mathrm{Nutr}$ 114,853-865.

Jeong, J. J. Ha Y. M. Jin Y. C. Lee E. J. Kim J. S. Kim H. J. Seo H. G. Lee J. H. Kang S. S. Kim Y. S. and Chang K. C., (2009). Rutin from Lonicera japonica inhibits myocardial ischemia/reperfusion-induced apoptosis in vivo and protects $\mathrm{H} 9 \mathrm{c} 2$ cells against hydrogen peroxide-mediated injury via ERK1/2 and PI3K/Akt signals in vitro. FOOD AND CHEMICAL TOXICOLOGY 47,1569-1576.

Jiang, X. Nie B. Fu S. Hu J. Yin L. Lin L. Wang X. Lu P. and Xu X. M., (2009). EGb761 protects hydrogen peroxide-induced death of spinal cord neurons through inhibition of intracellular ROS production and modulation of apoptotic regulating genes. JOURNAL OF MOLECULAR NEUROSCIENCE 38,103-113.

Jin, M. Li J. R. and Wu W., (2004). [Study on the antioxidative effect of Safflor Yellow]. Zhongguo Zhong Yao Za Zhi 29,447-449.

K.R.Narayana, M.S.Reddy, M.R.Chaluvadi, D.R.Krishna, . (2001). "Bioflavonoids classification, pharmacological, biochemical effects and therapeutic potential,". Indian Journal of Pharmacology, 33, 2-16.

Kandhare, A. D. Shivakumar V. Rajmane A. Ghosh P. and Bodhankar S. L., (2014). Evaluation of the neuroprotective effect of chrysin via modulation of endogenous biomarkers in a rat model of spinal cord injury. J Nat Med 68,586-603.

Kang, T. H. Hur J. Y. Kim H. B. Ryu J. H. and Kim S. Y., (2006). Neuroprotective effects of the cyanidin-3-O-beta-d-glucopyranoside isolated from mulberry fruit against cerebral ischemia. NEUROSCIENCE LETTERS 391,122-126. 
Khalatbary, A. R. and Ahmadvand H., (2011). Anti-inflammatory effect of the epigallocatechin gallate following spinal cord trauma in rat. Iran Biomed J 15,31-37.

Khalatbary, A. R. Tiraihi T. Boroujeni M. B. Ahmadvand H. Tavafi M. and Tamjidipoor A., (2010). Effects of epigallocatechin gallate on tissue protection and functional recovery after contusive spinal cord injury in rats. BRAIN RESEARCH 1306,168-175.

Kim, D. H. Heo S. D. Ahn M. J. Sim K. B. and Shin T. K., (2003). Activation of embryonic intermediate filaments contributes to glial scar formation after spinal cord injury in rats. Journal of Veterinary Science 4,109-112.

Kim, K. T. Nam T. K. Park Y. S. Kim Y. B. and Park S. W., (2011). Neuroprotective effect of anthocyanin on experimental traumatic spinal cord injury. J Korean Neurosurg Soc 49,205-211.

Kim, Y. H. Bang C. Y. Won E. K. Kim J. P. and Choung S. Y., (2009). Antioxidant activities of Vaccinium uliginosum L. extract and its active components. JOURNAL OF MEDICINAL FOOD 12,885-892.

Kim, Y. Jo S. H. Kim W. H. and Kweon O. K., (2015). Antioxidant and anti-inflammatory effects of intravenously injected adipose derived mesenchymal stem cells in dogs with acute spinal cord injury. Stem Cell Research \& Therapy 6,229.

Kimura, M. Umegaki K. Kasuya Y. Sugisawa A. and Higuchi M., (2002). The relation between single/double or repeated tea catechin ingestions and plasma antioxidant activity in humans. EUROPEAN JOURNAL OF CLINICAL NUTRITION 56,1186-1193.

Koc, R. K. Akdemir H. Kurtsoy A. Pasaoglu H. Kavuncu I. Pasaoglu A. and Karakucuk I., (1995). Lipid peroxidation in experimental spinal cord injury. Comparison of treatment with Ginkgo biloba, TRH and methylprednisolone. Res Exp Med (Berl) 195,117-123.

Kotakadi, V. S. Jin Y. Hofseth A. B. Ying L. Cui X. Volate S. Chumanevich A. Wood P. A. Price R. L. McNeal A. Singh U. P. Singh N. P. Nagarkatti M. Nagarkatti P. S. Matesic L. E. Auclair K. Wargovich M. J. and Hofseth L. J., (2008). Ginkgo biloba extract EGb 761 has anti-inflammatory properties and ameliorates colitis in mice by driving effector $\mathrm{T}$ cell apoptosis. CARCINOGENESIS 29,1799-1806.

Kumar, S. Sharma U. K. Sharma A. K. and Pandey A. K., (2012). Protective efficacy of Solanum xanthocarpum root extracts against free radical damage: phytochemical analysis and antioxidant effect. Cell Mol Biol (Noisy-le-grand) 58,174-181.

Kunihara, T. Sasaki S. Shiiya N. Ishikura H. Kawarada Y. Matsukawa A. and Yasuda K., (2000). Lazaroid reduces production of $\mathrm{IL}-8$ and IL-1 receptor antagonist in ischemic spinal cord injury. ANNALS OF THORACIC SURGERY 69,792-798.

Lawrence, M. C. Jivan A. Shao C. Duan L. Goad D. Zaganjor E. Osborne J. McGlynn K. Stippec S. Earnest S. Chen W. and Cobb M. H., (2008). The roles of MAPKs in disease. CELL RESEARCH 18,436-442.

Lee, K. H. Morris-Natschke S. L. Yang X. Huang R. Zhou T. Wu S. F. Shi Q. and Itokawa H., (2012). Recent progress of research on medicinal mushrooms, foods, and other herbal products used in traditional Chinese medicine. J Tradit Complement Med 2,84-95.

Li, J. X. Xue B. Chai Q. Liu Z. X. Zhao A. P. and Chen L. B., (2005). Antihypertensive effect of total flavonoid fraction of Astragalus complanatus in hypertensive rats. Chin J Physiol 48,101-106.

Li, L. Adnan H. Xu B. Wang J. Wang C. Li F. and Tang K., (2015). Effects of transplantation of olfactory ensheathing cells in chronic spinal cord injury: a systematic review and meta-analysis. EUROPEAN SPINE JOURNAL 24,919-930.

Lin, H. S. Ji Z. S. Zheng L. H. Guo G. Q. Chen B. Wu H. and Zhang G. W., (2012). Effect of 
methylprednisolone on the activities of caspase $-3,-6,-8$ and -9 in rabbits with acute spinal cord injury. Experimental and therapeutic medicine 4,49-54.

Lin, L. Wu X. D. Davey A. K. and Wang J., (2010). The anti-inflammatory effect of baicalin on hypoxia/reoxygenation and TNF-alpha induced injury in cultural rat cardiomyocytes. PHYTOTHERAPY RESEARCH 24,429-437.

Liu, J. Sun K. Zheng C. Chen X. Zhang W. Wang Z. Shar P. A. Xiao W. and Wang Y., (2015). Pathway as a pharmacological target for herbal medicines: an investigation from reduning injection. PLoS One 10,e0123109.

Liu, X. Z. Xu X. M. Hu R. Du C. Zhang S. X. McDonald J. W. Dong H. X. Wu Y. J. Fan G. S. Jacquin M. F. Hsu C. Y. and Choi D. W., (1997). Neuronal and glial apoptosis after traumatic spinal cord injury. JOURNAL OF NEUROSCIENCE 17,5395-5406.

Ma, Q. Ruan Y. Y. Xu H. Shi X. M. Wang Z. X. and Hu Y. L., (2015). Safflower yellow reduces lipid peroxidation, neuropathology, tau phosphorylation and ameliorates amyloid beta-induced impairment of learning and memory in rats. BIOMEDICINE \& PHARMACOTHERAPY 76,153-164.

Macready, A. L. George T. W. Chong M. F. Alimbetov D. S. Jin Y. Vidal A. Spencer J. P. Kennedy O. B. Tuohy K. M. Minihane A. M. Gordon M. H. Lovegrove J. A. and Group Flavurs Study. (2014). Flavonoid-rich fruit and vegetables improve microvascular reactivity and inflammatory status in men at risk of cardiovascular disease--FLAVURS: a randomized controlled trial. AMERICAN JOURNAL OF CLINICAL NUTRITION 99,479-489.

Magalingam, K. B. Radhakrishnan A. and Haleagrahara N., (2013). Rutin, a bioflavonoid antioxidant protects rat pheochromocytoma (PC-12) cells against 6-hydroxydopamine (6-OHDA)-induced neurotoxicity. INTERNATIONAL JOURNAL OF MOLECULAR MEDICINE 32,235-240.

Manach, C. Williamson G. Morand C. Scalbert A. and Remesy C., (2005). Bioavailability and bioefficacy of polyphenols in humans. I. Review of 97 bioavailability studies. AMERICAN JOURNAL OF CLINICAL NUTRITION 81,230S-242S.

Martinou, J. C. Dubois-Dauphin M. Staple J. K. Rodriguez I. Frankowski H. Missotten M. Albertini P. Talabot D. Catsicas S. Pietra C. and et al., (1994). Overexpression of BCL-2 in transgenic mice protects neurons from naturally occurring cell death and experimental ischemia. NEURON 13,1017-1030.

Matsunaga, K. Yoshimi N. Shimoi K. Yamada Y. Katayama M. Sakata K. Kumo T. Yoshida K. Qiao Z. Kinae N. and Mori H., (2000). Inhibitory Effects of Dietary Monoglucosyl-rutin on Azoxymethane-induced Colon Carcinogenesis in Rats. Asian Pac J Cancer Prev 1,211-216.

Mautes, A. E. Weinzierl M. R. Donovan F. and Noble L. J., (2000). Vascular events after spinal cord injury: contribution to secondary pathogenesis. PHYSICAL THERAPY 80,673-687.

Mechirova, E. Domorakova I. Dankova M. Danielisova V. and Burda J., (2009). Effect of noradrenalin and EGb 761 pretreatment on the ischemia-reperfusion injured spinal cord neurons in rabbits. CELLULAR AND MOLECULAR NEUROBIOLOGY 29,991-998.

Middleton, E., (1984). "The flavonoids,". TRENDS IN PHARMACOLOGICAL SCIENCES 5,335-338.

Nekoui, A. Del Carmen Escalante Tresierra V. Abdolmohammadi S. Shedid D. and Blaise G., (2015). Neuroprotective Effect of Erythropoietin in Postoperation Cervical Spinal Cord Injury: Case Report and Review. Anesth Pain Med 5,e28849.

Nwose, E. U. and Ewing G. W., (2009). Computer diagnosis in cardiology: oxidative stress hypothesis. N Am J Med Sci 1,220-225. 
Oraee-Yazdani, S. Hafizi M. Atashi A. Ashrafi F. Seddighi A. S. Hashemi S. M. Seddighi A. Soleimani M. and Zali A., (2016). Co-transplantation of autologous bone marrow mesenchymal stem cells and Schwann cells through cerebral spinal fluid for the treatment of patients with chronic spinal cord injury: safety and possible outcome. SPINAL CORD 54,102-109.

Pan, F. Cheng Y. X. Tao F. H. Zhu C. L. Li Z. H. Tao H. Y. He B. Yu L. Liu Y. and Tang H., (2013). [Protective effect of tacrolimus postconditioning on oxidative stress injury provoked by spinal cord ischemia-reperfusion in rats]. Zhonghua Yi Xue Za Zhi 93,3796-3800.

Petchkrua, W. Little J. W. Burns S. P. Stiens S. A. and James J. J., (2003). Vitamin B12 deficiency in spinal cord injury: a retrospective study. JOURNAL OF SPINAL CORD MEDICINE 26,116-121.

Popovich, P. G. Wei P. and Stokes B. T., (1997). Cellular inflammatory response after spinal cord injury in Sprague-Dawley and Lewis rats. JOURNAL OF COMPARATIVE NEUROLOGY 377,443-464.

Ramasamy, K. and Agarwal R., (2008). Multitargeted therapy of cancer by silymarin. CANCER LETTERS 269,352-362.

Renno, W. M. Al-Khaledi G. Mousa A. Karam S. M. Abul H. and Asfar S., (2014). (-)-Epigallocatechin-3-gallate (EGCG) modulates neurological function when intravenously infused in acute and, chronically injured spinal cord of adult rats. NEUROPHARMACOLOGY 77,100-119.

Rodrigues, A. M. Marcilio Fdos S. Frazao Muzitano M. and Giraldi-Guimaraes A., (2013). Therapeutic potential of treatment with the flavonoid rutin after cortical focal ischemia in rats. BRAIN RESEARCH 1503,53-61.

Romero, I. Teresa Sanchez-Ballesta M. Maldonado R. Isabel Escribano M. and Merodio C., (2008). Anthocyanin, antioxidant activity and stress-induced gene expression in high CO2-treated table grapes stored at low temperature. JOURNAL OF PLANT PHYSIOLOGY 165,522-530.

Saeed, M. Kadioglu O. Khalid H. Sugimoto Y. and Efferth T., (2015). Activity of the dietary flavonoid, apigenin, against multidrug-resistant tumor cells as determined by pharmacogenomics and molecular docking. JOURNAL OF NUTRITIONAL BIOCHEMISTRY 26,44-56.

Sang, H. F. Mei Q. B. Xu L. X. Wang Q. Cheng H. and Xiong L. Z., (2004). Effect of puerarin on neural function and histopathological damages after transient spinal cord ischemia in rabbits. Chin J Traumatol 7,143-147.

Schroder, K. and Tschopp J., (2010). The inflammasomes. CELL 140,821-832.

Schultke, E. Griebel R. W. and Juurlink B. H., (2010). Quercetin attenuates inflammatory processes after spinal cord injury in an animal model. SPINAL CORD 48,857-861.

Schultke, E. Kamencic H. Skihar V. M. Griebel R. and Juurlink B., (2010). Quercetin in an animal model of spinal cord compression injury: correlation of treatment duration with recovery of motor function. SPINAL CORD 48,112-117.

Sekhon, L. H. and Fehlings M. G., (2001). Epidemiology, demographics, and pathophysiology of acute spinal cord injury. Spine (Phila Pa 1976) 26,S2-12.

Shan, L. Q. Ma S. Qiu X. C. Zhou Y. Zhang Y. Zheng L. H. Ren P. C. Wang Y. C. Fan Q. Y. and Ma B. A., (2010). Hydroxysafflor Yellow A protects spinal cords from ischemia/reperfusion injury in rabbits. BMC NEUROSCIENCE 11,98.

Shang, Y. Z. Miao H. Cheng J. J. and Qi J. M., (2006). Effects of amelioration of total flavonoids from stems and leaves of Scutellaria baicalensis Georgi on cognitive deficits, neuronal damage and free radicals disorder induced by cerebral ischemia in rats. BIOLOGICAL \& PHARMACEUTICAL BULLETIN 29,805-810. 
Sharma, H. S. Gordh T. Wiklund L. Mohanty S. and Sjoquist P. O., (2006). Spinal cord injury induced heat shock protein expression is reduced by an antioxidant compound H-290/51. An experimental study using light and electron microscopy in the rat. J Neural Transm (Vienna) 113,521-536.

Shin, W. H. Park S. J. and Kim E. J., (2006). Protective effect of anthocyanins in middle cerebral artery occlusion and reperfusion model of cerebral ischemia in rats. LIFE SCIENCES 79,130-137.

Silva, N. A. Sousa N. Reis R. L. and Salgado A. J., (2014). From basics to clinical: a comprehensive review on spinal cord injury. PROGRESS IN NEUROBIOLOGY 114,25-57.

Singh, A. Tetreault L. Kalsi-Ryan S. Nouri A. and Fehlings M. G., (2014). Global prevalence and incidence of traumatic spinal cord injury. Clin Epidemiol 6,309-331.

Smith, J. S. Anderson R. Pham T. Bhatia N. Steward O. and Gupta R., (2010). Role of early surgical decompression of the intradural space after cervical spinal cord injury in an animal model. JOURNAL OF BONE AND JOINT SURGERY-AMERICAN VOLUME 92,1206-1214.

Song, K. Na J. Y. Kim S. and Kwon J., (2015). Rutin upregulates neurotrophic factors resulting in attenuation of ethanol-induced oxidative stress in HT22 hippocampal neuronal cells. J Sci Food Agric 95,2117-2123.

Srivastava, S. Somasagara R. R. Hegde M. Nishana M. Tadi S. K. Srivastava M. Choudhary B. and Raghavan S. C., (2016). Quercetin, a Natural Flavonoid Interacts with DNA, Arrests Cell Cycle and Causes Tumor Regression by Activating Mitochondrial Pathway of Apoptosis. Sci Rep 6,24049 .

Stahel, P. F. VanderHeiden T. and Finn M. A., (2012). Management strategies for acute spinal cord injury: current options and future perspectives. Current Opinion in Critical Care 18,651-660.

Steed, L. E. and Truong V. D., (2008). Anthocyanin content, antioxidant activity, and selected physical properties of flowable purple-fleshed sweetpotato purees. JOURNAL OF FOOD SCIENCE 73,S215-221.

Sternberg, Z. Chadha K. Lieberman A. Drake A. Hojnacki D. Weinstock-Guttman B. and Munschauer F., (2009). Immunomodulatory responses of peripheral blood mononuclear cells from multiple sclerosis patients upon in vitro incubation with the flavonoid luteolin: additive effects of IFN-beta. J Neuroinflammation 6,28.

Streit, W. J. Semple-Rowland S. L. Hurley S. D. Miller R. C. Popovich P. G. and Stokes B. T., (1998). Cytokine mRNA profiles in contused spinal cord and axotomized facial nucleus suggest a beneficial role for inflammation and gliosis. EXPERIMENTAL NEUROLOGY 152,74-87.

Suberviola, B. Gonzalez-Castro A. Llorca J. Ortiz-Melon F. and Minambres E., (2008). Early complications of high-dose methylprednisolone in acute spinal cord injury patients. INJURY-INTERNATIONAL JOURNAL OF THE CARE OF THE INJURED 39,748-752.

Thao, N. P. Luyen B. T. Widowati W. Fauziah N. Maesaroh M. Herlina T. Manzoor Z. Ali I. Koh Y. S. and Kim Y. H., (2016). Anti-inflammatory Flavonoid C-Glycosides from Piper aduncum Leaves. PLANTA MEDICA.

Tian, F. Xu L. H. Zhao W. Tian L. J. and Ji X. L., (2011). The optimal therapeutic timing and mechanism of puerarin treatment of spinal cord ischemia-reperfusion injury in rats. JOURNAL OF ETHNOPHARMACOLOGY 134,892-896.

_- _ (2013). The neuroprotective mechanism of puerarin treatment of acute spinal cord injury in rats. NEUROSCIENCE LETTERS 543,64-68.

Tian, W. Han X. G. Liu Y. J. Tang G. Q. Liu B. Wang Y. Q. Xiao B. and Xu Y. F., (2013). Intrathecal 
epigallocatechin gallate treatment improves functional recovery after spinal cord injury by upregulating the expression of BDNF and GDNF. NEUROCHEMICAL RESEARCH 38,772-779.

Toborek, M. Malecki A. Garrido R. Mattson M. P. Hennig B. and Young B., (1999). Arachidonic acid-induced oxidative injury to cultured spinal cord neurons. JOURNAL OF NEUROCHEMISTRY 73,684-692.

Tsai, M. J. Liao J. F. Lin D. Y. Huang M. C. Liou D. Y. Yang H. C. Lee H. J. Chen Y. T. Chi C. W. Huang W. C. and Cheng H., (2010). Silymarin protects spinal cord and cortical cells against oxidative stress and lipopolysaccharide stimulation. NEUROCHEMISTRY INTERNATIONAL 57,867-875.

Tsuji, P. A. Stephenson K. K. Wade K. L. Liu H. and Fahey J. W., (2013). Structure-activity analysis of flavonoids: direct and indirect antioxidant, and antiinflammatory potencies and toxicities. NUTRITION AND CANCER-AN INTERNATIONAL JOURNAL 65,1014-1025.

Walters, B. C. Hadley M. N. Hurlbert R. J. Aarabi B. Dhall S. S. Gelb D. E. Harrigan M. R. Rozelle C. J. Ryken T. C. Theodore N. American Association of Neurological Surgeons and Congress of Neurological Surgeons. (2013). Guidelines for the management of acute cervical spine and spinal cord injuries: 2013 update. NEUROSURGERY 60 Suppl 1,82-91.

Wang, J. Ma C. Rong W. Jing H. Hu X. Liu X. Jiang L. Wei F. and Liu Z., (2012). Bog bilberry anthocyanin extract improves motor functional recovery by multifaceted effects in spinal cord injury. NEUROCHEMICAL RESEARCH 37,2814-2825.

Wang, L. Zhao A. Wang F. Chai Q. and Chai X., (1997). [Protective effect of puerarin on acute cerebral ischemia in rats]. Zhongguo Zhong Yao Za Zhi 22,752-754, 765.

Wang, S. W. Wang Y. J. Su Y. J. Zhou W. W. Yang S. G. Zhang R. Zhao M. Li Y. N. Zhang Z. P. Zhan D. W. and Liu R. T., (2012). Rutin inhibits beta-amyloid aggregation and cytotoxicity, attenuates oxidative stress, and decreases the production of nitric oxide and proinflammatory cytokines. NEUROTOXICOLOGY 33,482-490.

Wang, Z. F. Liao D. G. and Li C. Q., (2010). [Effect of endogenous brain derived neurotrophic factor on GAP-43 expression in the anterior horn of the spinal cord in rats with sciatic nerve injury]. Nan Fang Yi Ke Da Xue Xue Bao 30,569-571.

Wei, H. Teng H. Huan W. Zhang S. Fu H. Chen F. Wang J. Wu C. and Zhao J., (2012). An upregulation of SENP3 after spinal cord injury: implications for neuronal apoptosis. NEUROCHEMICAL RESEARCH 37,2758-2766.

Wei, X. Liu H. Sun X. Fu F. Zhang X. Wang J. An J. and Ding H., (2005). Hydroxysafflor yellow A protects rat brains against ischemia-reperfusion injury by antioxidant action. NEUROSCIENCE LETTERS 386,58-62.

Wilson, J. R. and Fehlings M. G., (2014). Riluzole for acute traumatic spinal cord injury: a promising neuroprotective treatment strategy. World Neurosurgery 81,825-829.

Wu, J. Maoqiang L. Fan H. Zhenyu B. Qifang H. Xuepeng W. and Liulong Z., (2016). Rutin attenuates neuroinflammation in spinal cord injury rats. JOURNAL OF SURGICAL RESEARCH 203,331-337.

Xing, G. Dong M. Li X. Zou Y. Fan L. Wang X. Cai D. Li C. Zhou L. Liu J. and Niu Y., (2011). Neuroprotective effects of puerarin against beta-amyloid-induced neurotoxicity in PC12 cells via a PI3K-dependent signaling pathway. BRAIN RESEARCH BULLETIN 85,212-218.

Xu, B. and Chang S. K., (2009). Total Phenolic, Phenolic Acid, Anthocyanin, Flavan-3-ol, and Flavonol Profiles and Antioxidant Properties of Pinto and Black Beans ( Phaseolus vulgaris L.) as Affected by Thermal Processing. J Agric Food Chem 57,4754-4764.

Xu, P. X. Wang S. W. Yu X. L. Su Y. J. Wang T. Zhou W. W. Zhang H. Wang Y. J. and Liu R. T., (2014). Rutin 
improves spatial memory in Alzheimer's disease transgenic mice by reducing Abeta oligomer level and attenuating oxidative stress and neuroinflammation. BEHAVIOURAL BRAIN RESEARCH 264,173-180.

Xu, X. Zhang S. Zhang L. Yan W. and Zheng X., (2005). The Neuroprotection of puerarin against cerebral ischemia is associated with the prevention of apoptosis in rats. PLANTA MEDICA 71,585-591.

Yan, M. Liu Y. W. Shao W. Mao X. G. Yang M. Ye Z. X. Liang W. and Luo Z. J., (2016). EGb761 improves histological and functional recovery in rats with acute spinal cord contusion injury. SPINAL CORD 54,259-265.

Yang, L. Jones N. R. Blumbergs P. C. Van Den Heuvel C. Moore E. J. Manavis J. Sarvestani G. T. and Ghabriel M. N., (2005). Severity-dependent expression of pro-inflammatory cytokines in traumatic spinal cord injury in the rat. JOURNAL OF CLINICAL NEUROSCIENCE 12,276-284.

Ye, S. Y. and Gao W. Y., (2008). Hydroxysafflor yellow A protects neuron against hypoxia injury and suppresses inflammatory responses following focal ischemia reperfusion in rats. ARCHIVES OF PHARMACAL RESEARCH 31,1010-1015.

Yin, D. Li J. Lei X. Liu Y. Yang Z. and Chen K., (2014). Antiviral Activity of Total Flavonoid Extracts from Selaginella moellendorffii Hieron against Coxsackie Virus B3 In Vitro and In Vivo. Evid Based Complement Alternat Med 2014,950817.

Yiu, G. and He Z., (2006). Glial inhibition of CNS axon regeneration. Nature Reviews Neuroscience 7,617-627.

Yousefifard, M. Nasirinezhad F. Shardi Manaheji H. Janzadeh A. Hosseini M. and Keshavarz M., (2016). Human bone marrow-derived and umbilical cord-derived mesenchymal stem cells for alleviating neuropathic pain in a spinal cord injury model. Stem Cell Research \& Therapy 7,36.

Zendedel, A. Johann S. Mehrabi S. Joghataei M. T. Hassanzadeh G. Kipp M. and Beyer C., (2016). Activation and Regulation of NLRP3 Inflammasome by Intrathecal Application of SDF-1a in a Spinal Cord Injury Model. MOLECULAR NEUROBIOLOGY 53,3063-3075.

Zhai, H. W. Gong Z. K. Sun J. Chen W. Zhang M. Zhou J. J. and Zheng B., (2015). Ganglioside with nerve growth factor for the recovery of extremity function following spinal cord injury and somatosensory evoked potential. Eur Rev Med Pharmacol Sci 19,2282-2286.

Zhang, P. and Ma X., (2015). Effect of rutin on spinal cord injury through inhibition of the expression of MIP-2 and activation of MMP-9, and downregulation of Akt phosphorylation. Molecular Medicine Reports 12,7554-7560.

Zhang, Q. Yang H. An J. Zhang R. Chen B. and Hao D. J., (2016). Therapeutic Effects of Traditional Chinese Medicine on Spinal Cord Injury: A Promising Supplementary Treatment in Future. Evid Based Complement Alternat Med 2016,8958721.

Zhang, X. Feng G. Weng W. Liang J. Lin N. Cai Y. Xu R. Zhou N. Yuan M. Yuan W. and Xia X., (2009). Protective effects of baicalin and octreotide on intestinal mucosa of rats with severe acute pancreatitis. Turkish Journal of Gastroenterology 20,108-115.

Zhang, Y. Wang X. Wang X. Xu Z. Liu Z. Ni Q. Chu X. Qiu M. Zhao A. and Jia W., (2006). Protective effect of flavonoids from Scutellaria baicalensis Georgi on cerebral ischemia injury. JOURNAL OF ETHNOPHARMACOLOGY 108,355-360.

Zhao, J. F. Xie C. Xu S. Z. Ding M. W. and Xiao W. J., (2006). Iminophosphorane-mediated efficient synthesis of new tricyclic 3,5-dihydro-1,2,3-triazolo[4,5-d]-1,2,4-triazolo[1,5-a]pyrimidin-9-ones. ORGANIC＆ BIOMOLECULAR CHEMISTRY 4,130-134. 
Zhao, Z. Liu N. Huang J. Lu P. H. and Xu X. M., (2011). Inhibition of cPLA2 activation by Ginkgo biloba extract protects spinal cord neurons from glutamate excitotoxicity and oxidative stress-induced cell death. JOURNAL OF NEUROCHEMISTRY 116,1057-1065.

Zhou, D. Liu B. Xiao X. Dai P. Ma S. and Huang W., (2013). The effect of safflower yellow on spinal cord ischemia reperfusion injury in rabbits. Oxidative Medicine and Cellular Longevity 2013,692302.

Zhou, P. Q. Shen L. Yang Y. P. and Xie J., (2006). [Clinical observation of puerarin in treating patients with vertebral artery insufficiency due to cervical spondylosis: a report of 123 cases]. Zhong Xi Yi Jie He Xue Bao 4,80-81.

Zhu, H. B. Zhang L. Wang Z. H. Tian J. W. Fu F. H. Liu K. and Li C. L., (2005). Therapeutic effects of hydroxysafflor yellow $A$ on focal cerebral ischemic injury in rats and its primary mechanisms. JOURNAL OF ASIAN NATURAL PRODUCTS RESEARCH 7,607-613. 